\title{
Technical aids and housing adaptations among very old people with self-reported Parkinson's disease compared to matched controls
}

This article was published in the following Dove Press journal:

Journal of Parkinsonism and Restless Legs Syndrome

10 June 2013

Number of times this article has been viewed

\author{
Maria Haak \\ Björn Slaug \\ Charlotte Löfquist \\ Maria $\mathrm{H}$ Nilsson \\ Department of Health Sciences, Lund \\ University, Lund, Sweden
}

Background and aim: This study aimed to explore the use and perceived unmet need of technical aids and housing adaptations among very old people, living alone in ordinary housing with self-reported Parkinson's disease, compared to matched controls.

Methods: Data collected in the European ENABLE-AGE study were used to identify people with self-reported Parkinson's disease $(n=20)$ and to select three matched controls per individual $(n=60)$. The matching criteria were age (mean $=82$ years), sex, country, and type of housing. Analyses targeted use and perceived unmet need of technical aids and housing adaptations.

Results: Very old people with self-reported Parkinson's disease use significantly more aids for personal mobility than very old people in general. They have, furthermore, a significant increased unmet need concerning aids for personal care and protection. Housing adaptations did not differ between the two groups.

Conclusion: Since people with Parkinson's disease use technical aids to a higher extent and express an unmet need, they may require more thorough counseling regarding technical aids. Thus, this explorative study provides important information for health care professionals, rehabilitation, and future research. Moreover, in order to develop knowledge about specific challenges connected to Parkinson's disease among the very old, further and larger studies targeting environmental resources are needed. Such studies should preferably include people with a verified diagnosis.

Keywords: technical aids, environment, rehabilitation, activities of daily life

\section{Introduction}

Environmental resources ${ }^{1}$ such as technical aids (TAs) and housing adaptations (HAs) are of utmost importance for very old people's lives in order to participate and carry out daily life as independent as possible. ${ }^{2} \mathrm{~A}$ common chronic progressive neurological disease that predominantly affects very old people is Parkinson's disease (PD). ${ }^{3,4}$ People with PD often experience a progressive decline in motor function, eg, tremor, rigidity, bradykinesia, and postural instability. ${ }^{5}$ Their experienced symptoms negatively affect the ability to perform everyday activities. ${ }^{6}$ More specifically, compared with others of the same age, people with PD particularly have difficulties in more complex activities (eg, shopping and using transportation), for which TAs such as walking sticks and rollators can be helpful. TAs are often used to compensate for functional limitations and to overcome environmental demands, ${ }^{7}$ and improve activity and participation among users. ${ }^{8}$ The use and need of TAs have been investigated in relation to a general aging population, ${ }^{9,10}$ but PD research targeting TAs has mainly focused on mobility
Correspondence: Maria Haak Department of Health Sciences, Faculty of Medicine, Lund University, Box 157, Lund 221 00, Sweden $\mathrm{Tel}+46462221815$

Fax +46 462221959

Email maria.haak@med.lu.se
Journal of Parkinsonism and Restless Legs Syndrome 2013:3 4I-47

(C) 2013 Haak et al, publisher and licensee Dove Medical Press Ltd. This is an Open Access article

Dovepress

http://dx.doi.org./10.2147JJPRLS.S44329 
devices for gait. ${ }^{11,12}$ Consequently, even though PD is typical for old age, there is scarce knowledge about the use of and perceived unmet need for TAs while aging with PD.

$\mathrm{HA}$ is another environmental resource that may facilitate managing daily life as independently as wished, and it has therefore been advocated that geriatricians should ensure that their patients are informed of possibilities for HA. ${ }^{13}$ Even though aging with a chronic and progressive disease forces specific challenges on the housing environment, research in the field of HA and PD is virtually nonexistent. Thus, knowledge on whether the situation of people with PD differs from that of aging in general is scarce.

Turning to prior research within PD, so far the focus has been on body function rather than environmental resources of importance to manage everyday life. In the area of environmental resources, we find studies examining economic effects of PD or those having Parkinsonian symptoms. ${ }^{14,15}$ More specifically, a recent study ${ }^{16}$ showed that people with PD or having Parkinsonian symptoms were using medicine to a higher extent and had more than three times higher medical costs than matched controls. Moreover, they were more likely to receive welfare payments.

To sum up concerning environmental resources and PD, there is a gap and a critical need to integrate clinical research with research also taking aspects of everyday life into account. The aim of this study was therefore to explore the use and perceived unmet need of TAs in very old people, living alone in ordinary housing with self-reported PD, compared to matched controls. An additional aim was to explore whether HA differed between the two groups.

\section{Participants and methods Project context}

This study was based on data from the ENABLE-AGE survey study, ${ }^{17}$ gathered in Sweden, Germany, the UK, Hungary, and Latvia. The target sample in each country was very old people (75-89 years), living in single-person households in urban areas. The total sample included 1918 participants (78\% women). All participants were enrolled after informed consent, following the Helsinki Declaration and the ethical guidelines of each country. After training, interviewers collected data at home visits. ${ }^{18}$ Details on ENABLE-AGE have been published elsewhere. ${ }^{17,19}$

\section{Study samples}

The present study was a cross-sectional comparison between two subsamples retrieved from the international ENABLE-AGE database. One subsample comprised all individuals that reported having PD (PD sample) according to structured questions based on the International Classification of Diseases, version 10. PD had been diagnosed by a physician or neurologist outside the ENABLE-AGE survey study. The other subsample constituted a matched-control sample. Twenty-one individuals with self-reported PD were identified in the total sample. One Hungarian woman was excluded due to extensive missing data. The final PD sample consisted of 20 individuals (15 women and 5 men, mean age 82 years).

Each individual with self-reported PD was individually matched with three controls ${ }^{20}$ from the ENABLE-AGE database. The matching criteria were sex, country, age ( \pm 1 year), and type of housing (Table 1). By means of the software R version 2.12.1 (2010, R Development Core Team, KS, USA), the three controls were randomly selected among all individuals fulfilling the matching criteria. ${ }^{20}$ The matched-control sample included 60 individuals (45 women, 15 men, mean age 82 years).

\section{Assessments}

Data collection was conducted during a structured interview in the home environment. Except for self-reported PD, the interviewer also collected data on other self-reported diseases during the last year. The list of diseases (from the International Classification of Diseases) included dementia, eye diseases (ie, glaucoma, cataract and macular degeneration), stroke, and osteoporosis. In addition, data on symptoms were collected by the question: "Have you been troubled by any of the following symptoms during the last three months? Please answer 'yes' or 'no': dizziness; general fatigue; pain in the joints; backache and pain in the legs" (Table 2).

Table I Matching variables, PD sample $(n=20)$, and matched controls $(n=60)$

\begin{tabular}{lll}
\hline Variable & PD sample & Controls \\
\hline Age, mean (SD, range) & $82(3.6,76-90)$ & $82(3.6,76-91)$ \\
Sex, women/men (\% men) & $15 / 5(25)$ & $45 / 15(25)$ \\
Type of housing, n (\%) & & \\
$\quad$ Multidwelling block & $16(80)$ & $48(80)$ \\
One-family house & $2(10)$ & $6(10)$ \\
Semidetached/two-family house & $\mathrm{I}(5)$ & $3(5)$ \\
Other & $\mathrm{I}(5)$ & $3(5)$ \\
Country, n (\%) & & \\
Germany & $4(20)$ & $12(20)$ \\
Hungary & $7(35)$ & $2 \mathrm{I}(35)$ \\
Latvia & $4(20)$ & $12(20)$ \\
Sweden & $\mathrm{I}(5)$ & $3(5)$ \\
United Kingdom & $4(20)$ & $12(20)$ \\
\hline
\end{tabular}

Abbreviations: PD, Parkinson's disease (self-reported); SD, standard deviation. 
Table 2 Sample characteristics, PD sample $(n=20)$, and matched controls $(n=60)$

\begin{tabular}{|c|c|c|}
\hline Variable & PD sample & Controls' \\
\hline \multicolumn{3}{|l|}{ Self-reported diagnoses } \\
\hline Dementia, n (\%) & $2(10)$ & $0(0)$ \\
\hline Cerebral insult, $\mathrm{n}(\%)$ & $2(10)$ & I (2) \\
\hline Eye diseases, $\mathrm{n}(\%)^{2}$ & $8(40)$ & $14(23)$ \\
\hline Osteoporosis, n (\%) & $10(50)$ & $21(35)$ \\
\hline \multicolumn{3}{|l|}{ Symptoms } \\
\hline Backache, n (\%) & $14(70)$ & $32(53)$ \\
\hline Dizziness, n (\%) & II (55) & $29(48)$ \\
\hline General fatigue, n (\%) & $15(75)$ & $37(62)$ \\
\hline Pain in the joints, $n(\%)$ & $17(85)$ & $40(67)$ \\
\hline Pain in the legs, $n(\%)$ & $15(75)$ & $37(62)$ \\
\hline
\end{tabular}

Notes: 'None of the controls reported PD; ${ }^{2}$ eye diseases included glaucoma, cataract, and macular degeneration; $100 \%$ of the PD sample and $90 \%$ of the controls were on some kind of medication.

Abbreviation: PD, Parkinson's disease (self-reported).

For the current study, project-specific questions within the ENABLE-AGE survey study questionnaire were used that targeted aspects of environmental resources: use and perceived unmet need of TAs and HAs and perceived financial situation.

For the assessment of the use and perceived unmet need of TAs, a study-specific part of the questionnaire contained questions regarding different TAs, ordered according to the International Organizational for Standardization (ISO) 9999 classification..$^{21}$ The ISO is a worldwide organization that established a classification for technical aids, facilitating comparisons regarding TAs both within and across countries. In this study, the following ISO classes were included: aids for personal care and protection (ISO class 09); personal mobility (ISO class 12); housekeeping (ISO class 15); and communication, information, and signaling (ISO class 21). ${ }^{21}$ In total, 25 questions targeted TAs in the different ISO domains. For each TA listed in the questionnaire, the participants were asked to answer whether they had, had and used, or felt a perceived unmet need for the respective type of TA. For each TA, the participant could thus choose more than one response option.

In addition, project-specific questions captured whether (and if so, where) any HAs had been made: "Have you had housing adaptation done? (Yes/No)," and if responding yes, "Where was the adaptation done?" The response options for specifying location were the following: outdoor environment; entrance; indoor environment, general; kitchen; hygiene area; or "Other, please specify."

For descriptive purposes, we also used four projectspecific questions targeting participants' financial situations (Table 3). Two dichotomous questions (no/yes) concerned
Table 3 Financial situation, PD sample $(n=20)$, and matched controls $(n=60)$

\begin{tabular}{lll}
\hline Financial situation & PD sample & Controls \\
\hline $\begin{array}{l}\text { How would you evaluate your household } \\
\text { income on a global level? }\end{array}$ & & \\
$\quad$ Low, n (\%) & $8(40)$ & $29(48)$ \\
$\quad$ Medium/normal, n (\%) & $10(50)$ & $27(45)$ \\
$\quad$ High, n (\%) & $2(10)$ & $3(5)$ \\
$\begin{array}{l}\text { Do you have a pension? n (\%) } \\
\text { Do you have social welfare? n (\%) })^{\mathrm{a}, \mathrm{b}, \mathrm{c}}\end{array}$ & $20(100)$ & $59(98)$ \\
$\begin{array}{l}\text { Do you have a housing allowance? n (\%) }{ }^{\mathrm{a}, \mathrm{c}} \\
\text { Do you have other sources of }\end{array}$ & $3(150)$ & $9(15)$ \\
income? n (\%) & $7(35)$ & $8(13)$ \\
$\begin{array}{l}\text { How satisfied are you with your financial } \\
\text { situation? median (qI-q3) }\end{array}$ & $5(3-8)$ & $5(20)$ \\
\hline
\end{tabular}

Notes: ${ }^{N}$ None of the included variables showed any statistically significant difference between the two groups; 'one of the controls had a missing value; 'one participant in the PD sample had a missing value; 'two of the controls had missing values; ${ }^{\mathrm{e}}$ rated from 0 (very unsatisfied) to 10 (very satisfied).

Abbreviation: PD, Parkinson's disease (self-reported).

whether the participants received pension and/or social welfare. Another two questions concerned how they perceived their financial situation. (1) "All in all, how satisfied are you with the financial situation of your household?" This was rated from 0 (very unsatisfied) to 10 (very satisfied). (2) "How would you evaluate your household income on a global level?" This was rated as low, average/medium, or high.

\section{Data analysis}

Internal missing data were treated in the following way. If there was a missing value for one of the individuals reporting $\mathrm{PD}$, all the controls belonging to that individual were also excluded from the particular analysis. If there was a missing value for one or two of the controls, the individual reporting PD and the remaining controls were included in the analysis.

Fisher's exact test was used when comparing the groups with regard to dichotomous variables. For group comparisons of variables with data on an ordinal scale, the Mann-Whitney test was used. All statistical tests were performed using SAS 9.2 for Windows (SAS Institute, Cary, NC, USA).

Given the exploratory nature of this study, no correction for multiple tests was applied. That is, results with $P$-values $<0.05$ were considered statistically significant.

\section{Results}

In relation to TAs (Table 4$)$, significantly more $(P=0.042)$ participants in the PD sample used aids for mobility, ie, $55 \%$ versus $30 \%$ for controls. An additional $20 \%$ of the PD sample reported having aids for mobility, but stated that they did not use them (see note, Table 4). 
Table 4 Use and perceived unmet need of technical aids (ISO-classified) in the PD sample compared $(n=20)$ with matched controls $(n=60)$

\begin{tabular}{|c|c|c|c|c|c|c|c|}
\hline \multirow{2}{*}{$\begin{array}{l}\text { ISO } \\
\text { class }\end{array}$} & \multirow[t]{2}{*}{ Technical aids } & \multicolumn{2}{|l|}{ In use } & \multirow[t]{2}{*}{$P$-value ${ }^{a}$} & \multicolumn{2}{|c|}{ Perceived unmet need } & \multirow[t]{2}{*}{$P$-value } \\
\hline & & $\begin{array}{l}\text { PD sample } \\
\text { n (\%) }\end{array}$ & $\begin{array}{l}\text { Controls } \\
\text { n (\%) }\end{array}$ & & $\begin{array}{l}\text { PD sample } \\
\text { n (\%) }\end{array}$ & $\begin{array}{l}\text { Controls } \\
\text { n (\%) }\end{array}$ & \\
\hline 09 & $\begin{array}{l}\text { Aids for personal care and protection }{ }^{\mathrm{b}} \\
\text { (eg, shower/bath, toileting) }\end{array}$ & $4(20)$ & $10(17)$ & 0.485 & $4(20)$ & $2(3)$ & 0.032 \\
\hline \multirow[t]{6}{*}{12} & Aids for personal mobilityc & II (55) & $18(30)$ & 0.042 & I (5) & $3(5)$ & 0.692 \\
\hline & Walking frame & $2(10)$ & $2(3)$ & 0.259 & I (5) & $2(3)$ & 0.583 \\
\hline & Rollator & $3(15)$ & $5(8)$ & 0.405 & $\mathrm{I}(5)$ & $0(0)$ & 0.250 \\
\hline & Walking stick & $9(45)$ & $16(27)$ & 0.165 & $0(0)$ & I (2) & 0.750 \\
\hline & Crutches & I (5) & $0(0)$ & 0.250 & $0(0)$ & $0(0)$ & - \\
\hline & Wheelchair (manual) & I (5) & I (2) & 0.440 & $0(0)$ & $0(0)$ & - \\
\hline 15 & $\begin{array}{l}\text { Aids for housekeeping } \\
\text { (eg, household, feeding) }\end{array}$ & $0(0)$ & $0(0)$ & - & $3(15)$ & $2(3)$ & 0.097 \\
\hline 21 & $\begin{array}{l}\text { Aids for communication }{ }^{\mathrm{de} e} \text { (eg, hand/ } \\
\text { stand magnifier, hearing aid) }\end{array}$ & $17(85)$ & $53(88)$ & 0.479 & I (5) & $I(2)$ & 0.440 \\
\hline
\end{tabular}

Notes: ${ }^{a}$ Significant $P$-values marked in bold; ban additional $2 \%$ of the controls reported that they had aids for personal care and protection, but that they did not use it/them; can additional $20 \%$ of the PD sample and I5\% of the controls reported that they had aids for personal mobility, but that they did not use it/them; ${ }^{d}$ an additional $5 \%$ of the PD sample and $7 \%$ of the controls reported they had aids for communication, but that they did not use it/them; eif excluding reading glasses, $60 \%$ of the PD sample and $43 \%$ of the controls reported that they used aids for communication. $P=0.151$. There were no missing values.

Abbreviations: PD, Parkinson's disease (self-reported); ISO, International Organization for Standardization.

The corresponding value was $15 \%$ for controls. In both samples, none used aids for housekeeping. The two groups furthermore showed no statistically significant $(P \geq 0.259)$ differences regarding use of aids for personal care and protection. However, the PD sample reported a significantly higher $(P=0.032)$ unmet need in relation to aids for personal care and protection, ie, 4/20 (20\%) versus 2/60 (3\%) for controls (Table 4).

Twenty percent of the PD sample reported having had an HA, whereas the corresponding value was $5 \%$ for controls (Table 5). This difference, however, did not reach statistical significance $(P=0.062)$. When exploring locations of the HA, significantly more $(P=0.032)$ participants in the $\mathrm{PD}$ sample reported having had an HA in the hygiene area. Other HA

Table 5 Housing adaptations and PD sample $(n=20)$ compared with matched controls $(n=60)$

\begin{tabular}{llll}
\hline Housing adaptations & $\begin{array}{l}\text { PD sample } \\
\mathbf{n}(\%)\end{array}$ & $\begin{array}{l}\text { Controls } \\
\mathbf{n}(\%)\end{array}$ & P-value $^{\mathbf{a}}$ \\
\hline $\begin{array}{l}\text { Have you had any housing } \\
\text { adaptation? }\end{array}$ & $4(20)$ & $3(5)$ & 0.062 \\
$\begin{array}{l}\text { Location of housing adaptation } \\
\text { butdoors }\end{array}$ & & \\
On (0) & I (2) & 0.750 \\
Entrance & I (5) & I (2) & 0.440 \\
Indoors, general & I (5) & $2(3)$ & 0.583 \\
Kitchen & $0(0)$ & I (2) & 0.750 \\
Hygiene area & $4(20)$ & $2(3)$ & $\mathbf{0 . 0 3 2}$ \\
Other location & $0(0)$ & I (2) & 0.750 \\
\hline
\end{tabular}

Notes: aSignificant $P$-values marked in bold; bthere may be housing adaptations in more than one location. There were no missing values.

Abbreviation: PD, Parkinson's disease (self-reported). locations showed no significant $(P>0.440)$ differences between the two groups (Table 5).

\section{Discussion}

This explorative study shows that very old people with selfreported PD use significantly more aids for personal mobility than very old people in general, including having a significant perceived unmet need for aids intended for personal care and protection. The fact that they report a perceived unmet need concerning TAs needs to be recognized in clinical practice. Moreover, it is of great importance to conduct further research of this kind, since it is obvious that very old people with self-reported PD have a perceived and unmet need for basic and simple TAs.

Aids for mobility were significantly more common among participants in the PD sample than in controls, which is not a surprising finding, since gait and balance problems (including falls and fear of falling) are common among people with PD. ${ }^{22-24}$ Since PD is a progressive disease, these problems deteriorate over time, and current anti-PD medications insufficiently address balance problems. This highlights the need to deepen knowledge about environmental recourses ${ }^{25}$ and their effects on everyday life for people with PD. One aspect to consider is additional treatment options (eg, rehabilitation) and embracing monitoring of TA use and need on a regular basis. Although TAs have been shown to increase independence and participation, ${ }^{26}$ it is of outmost importance that aids for mobility are appropriate both to the user when performing activities and the user's environment. 
Furthermore, in order to facilitate activities and participation, adequate and regular follow-ups are needed to ensure both safe and efficient use. ${ }^{26}$ For people with PD, a recent Cochrane review concluded furthermore that physical therapy significantly improves outcomes of walking, mobility, and balance compared with no intervention. ${ }^{27}$ The majority of the included studies had however a short follow-up period, and the effects were generally small. There is in fact a lack of rehabilitation studies specifically targeting very old people with $\mathrm{PD}$ and environmental resources. Moreover, very old people with PD are mostly excluded in PD research. ${ }^{28}$ Consequently, there is a need for future research that specifically addresses environmental factors such as TAs among very old people with PD. This is of importance due to the increased life expectancy not only for the general population but also for those living with chronic diseases such as PD.

For very old people both with and without selfreported $\mathrm{PD}$, the most commonly used TAs were aids for communication, eg, eyeglasses, hand/stand magnifier, hearing aids. In fact, these were used by $85 \%$ of the participants having self-reported PD versus $88 \%$ for controls. Although people with PD are known to have speech difficulties, ${ }^{29,30}$ we were somewhat surprised by the high values also for controls, though it needs to be noted that this category of aids included eyeglasses, which is a common TA in old age.

Although none in the respective groups reported using aids for housekeeping (eg, household, feeding), 15\% of the participants in the PD sample reported a perceived unmet need versus 3\% for controls. Even if this difference did not reach statistical significance, our findings may suggest that this is something to address specifically when screening for the need for TAs in very old people that have PD symptoms. This may also apply to aids for personal care and protection, where $4 / 20(20 \%)$ of the participants in the PD sample reported a perceived unmet need. It needs, however, to be underlined that a perceived unmet need may not be equivalent to a need as assessed by professionals. Even so, high need for TAs has also been reported in other studies on the very old population. ${ }^{9,31}$ Possible reasons for living with an unmet need could be lack of knowledge of different available devices. Thus, it is important to have knowledge about different kinds of existing devices in order to be able to express a need. Moreover, another study investigating the experiences of unmet TA need in older people in general showed that people struggled to manage everyday life and carefully considered usability and meaningfulness of a TA before taking further actions applying for the same. ${ }^{10}$
In relation to the proportion of participants that had attained HAs, our results showed no significant difference between the two groups. This finding may in fact purely reflect the original sampling that only targeted very old people, single, and living in ordinary housing. That is, our results may not apply to those that are severely affected by PD, since people with PD are more likely to be placed in assisted living and at an earlier age, causing high costs to society. ${ }^{14}$ An interesting finding was that most HAs for the PD sample was located in the hygiene area, despite the fact that they most commonly fall in bedrooms, living areas, or kitchens. ${ }^{32-34}$ That most HAs are located to the hygiene area is confirmed by another study. ${ }^{35}$ However, in a prospective study that targeted falls in people with $\mathrm{PD}$, only $8 \%$ of all falls occurred in the bathroom. ${ }^{32}$ Our finding, then, again highlights the importance from a professional perspective of taking the specific challenges of PD into account when making HA interventions. In the PD sample, no HAs were reported in the kitchen area, however there was a higher extent of perceived unmet need of aids for housekeeping. These findings could be interpreted such that there are difficulties handling activities in relation to cooking, and increased focus on HA interventions in the kitchen should be addressed, since these two environmental interventions in terms of HAs and TAs are highly linked. Often, HAs and TAs interact in a positive direction, and thus for tailored interventions both environmental resources need to be considered in order to facilitate activity and participation for people with PD.

Some study limitations need to be taken into account when interpreting our results. The matching criteria for the controls were limited to sex, country, age, and type of housing, and we cannot exclude that there may be other aspects of importance, such as comorbidities. Further, the PD diagnosis was based on self-report and had been diagnosed by a physician or neurologist outside the survey study. Since physicians who rarely diagnose PD may find this difficult, a patient should preferably be referred to a specialist in movement disorders. It is thus a limitation that we could not certify that all our participants had been diagnosed by a specialist, but also that we lacked descriptive data concerning PD-specific symptoms and medications. Future studies are thus needed, including those with a verified PD diagnosis. Despite these limitations, this explorative study provides important information for health professionals as well as for future research. People with PD are known to have comorbidities. ${ }^{36}$ Symptoms such as pain and fatigue are common among people with $\mathrm{PD}$, and in order not to diminish 
the external validity of our findings, these individuals were not excluded from the study.

The external validity of our findings is affected by the original sampling in the ENABLE-AGE project. It targeted a selected portion of people in very old age and did not represent the population in general, but rather a healthier segment in a European context. Furthermore, it aimed at reflecting the dominance of women in the very old population and consisted of $78 \%$ women. This explains the female preponderance in the PD sample, despite the fact that PD is more common among men. ${ }^{4}$ The original sample only included single-living participants in ordinary housing. Since people with PD are more commonly admitted to assisted living and at an earlier age, ${ }^{14}$ this may explain the somewhat low prevalence rate of PD (about $1 \%$ of the original crossnational database, $\mathrm{n}=1918$ ).

Moreover, it should be kept in mind that differences in health care and social services in different countries most likely influence access to TAs and prerequisites for HAs. In addition, multiple comparisons were done, which necessitates cautious interpretation of our findings. This explorative study is, however, highly novel and contributes to the body of knowledge. Notwithstanding the limitations discussed, the ENABLE-AGE project rests on solid methodology, ${ }^{19,37}$ and due to the large database available $(n=1918)$, we were able to apply a strong design with three matched controls per case. $^{20}$

\section{Conclusion}

Since people with PD use TAs to a higher extent, as well as express an unmet need, they may require more thorough counseling regarding TAs. This explorative study therefore provides important information for health care professionals, rehabilitation, and future research. In order to develop knowledge about specific challenges connected to PD among the very old, further and larger studies targeting environmental resources are needed, including people with a PD diagnosis that is verified according to standardized criteria.

\section{Acknowledgments}

The project "Enabling Autonomy, Participation, and WellBeing in Old Age: The Home Environment as a Determinant for Healthy Ageing" (ENABLE-AGE) was funded by the European Commission (QLRT-2001-00334). This paper was supported by funding from MultiPark, the Swedish Research Council, and the Swedish Research Council for Working Life and Social Research, and accomplished within the context of the Centre for Ageing and Supportive Environments (CASE), Lund University, Sweden.

\section{Disclosure}

The authors report no conflicts of interest in this work.

\section{References}

1. World Health Organization. International Classification of Functioning, Disability and Health. Geneva: WHO; 2001.

2. Iwarsson S. Assessing the fit between older people and their home environment - an occupational therapy perspective. In: Wahl HW, Scheidt R, Windley P, editors. Annual Review of the Gerontological Society of America: Focus on Aging in Context - Socio-physical Environments. New York: Springer; 2004:85-109.

3. Clarke C. Parkinson's disease. BMJ. 2007;335:441-445.

4. Wirdefeldt K, Adami HO, Cole P, Trichopoulos D, Mandel J. Epidemiology and etiology of Parkinson's disease: a review of the evidence. Eur J Epidemiol. 2011;26 Suppl 1:S1-S58.

5. Jankovic J. Parkinson's disease: clinical features and diagnosis. J Neurol Neurosurg Psychiatry. 2008;79:368-376.

6. Hariz GM, Forsgren L. Activities of daily living and quality of life in persons with newly diagnosed Parkinson's disease according to subtype of disease, and in comparison to healthy controls. Acta Neurol Scand. 2011;123(1):20-27.

7. Cook MH, Hussey SM. Assistive Technologies: Principles and Practice. St Louis: Mosby; 2002.

8. Salminen A, Brandt Å, Samuelsson K, Toytari O, Malmivaara A. Mobility devices to promote activity and participation: a systematic review. J Rehabil Med. 2009;41:697-706.

9. Löfqvist C, Nygren C, Széman Z, Iwarsson S. Assistive devices among very old people in five European countries. Scand J Occup Ther. 2005;12:181-192.

10. Gramstad A, Storli SL, Hamran T. "Do I need it? Do I really need it?" Elderly peoples experiences of unmet assistive technology device needs. Disabil Rehabil Assist Technol. Epub July 17, 2012.

11. Bryant MS, Pourmoghaddam A, Thrasher A. Gait changes with walking device in persons with Parkinson's disease. Disabil Rehabil Assist Technol. 2012;7:149-152.

12. Constantinescu R, Leonard C, Deeley C, Kurlan R. Assistive devices for gait in Parkinson's disease. Parkinsonism Relat Disord. 2007;13: 133-138.

13. Donald I. Housing and health care for older people. Age Ageing. 2009;38:364-367.

14. Vossius C, Nilsen OB, Larsen JP. Parkinson's disease and nursing home placement: the economic impact of the need for care. Eur J Neurol. 2009;16:194-200.

15. Reese SL. Psychosocial factors in Parkinson's disease. Dis Mon. 2007;53:291-295.

16. Jennum P, Zoetmulder M, Korbo L, Kjellberg J. The health-related, social and economic consequences of parkinsonism: a controlled national study. J Neurol. 2011;258:1497-1506.

17. Iwarsson S, Wahl HW, Nygren C, et al. Importance of the home environment for healthy aging: conceptual and methodological background of the European ENABLE-AGE project. Gerontologist. 2007;47:78-84.

18. Iwarsson S, Wahl HW, Nygren C. Challenges of cross-national housing research with older persons: lessons from the ENABLE-AGE project. Eur J Ageing. 2004;1:79-88.

19. Oswald F, Wahl HW, W, Shilling O, et al. Relationships between housing and healthy aging in very old age. Gerontologist. 2007;47:96-107.

20. Grimes D, Schulz K. Compared to what? Finding controls for case-control studies. Lancet. 2005;365:1429-1433.

21. International Organization for Standardization. Technical Aids for Persons with Disabilities: Classification and Terminology. Geneva: ISO; 2002. 
22. Kerr GK, Worringham CJ, Cole MH, Lacherez PF, Wood JM, Silburn PA. Predictors of future falls in Parkinson disease. Neurology. 2010;75:116-124.

23. Nilsson M, Hariz G, Iwarsson S, Hagell P. Walking ability is a major contributor to fear of falling in people with Parkinson's disease: implications for rehabilitation. Parkinson's Dis. 2012;2012:713236.

24. Schrag A, Ben-Shlomo Y, Quinn N. How common are complications of Parkinson's disease? J Neurol. 2002;249:419-423.

25. Schneidert M, Hurst R, Miller J, Üstün B. The role of environment in the International Classification of Functioning, Disability and Health (ICF). Disabil Rehabil. 2003;25:588-595.

26. World Health Organization. World Report on Disability. Geneva: WHO; 2011

27. Tomlinson C, Patel S, Meek C, et al. Physiotherapy versus placebo or no intervention in Parkinson's disease. Cochrane Database Syst Rev. 2012;8:CD002817.

28. Fitzsimmons P, Blayney S, Min-Corkill S, Scott G. Older participants are frequently excluded from Parkinson's disease research. Parkinsonism Relat Disord. 2012;18:585-589.

29. Sapir S, Pawlas A, Ramig L, et al. Voice and speech abnormalities in Parkinson's disease: Relation to severity of motor impairment, duration of disease, medication, depression, gender, and age. J Med Speech Lang Pathol. 2001;9:213-226.

30. Streifler M, Hofman S. Disorders of verbal expression in Parkinsonism Adv Neurol. 1984;40:385-393.
31. De Craen A, Westendorp R, Willems C, Buskens I, Gussekloo J. Assistive devices and community based services among 85-year-old community-dwelling elderly in the Netherlands: ownership, use, and need for intervention. Disabil Rehabil Assist Technol. 2006;1: 199-203.

32. Ashburn A, Stack E, Ballinger C, Fazakarley L, Fittion C. The circumstances of falls among people with Parkinson's disease and the use of falls diaries to facilitate reporting. Disabil Rehabil. 2008;30: 1205-1212.

33. Stack E, Ashburn A. Fall events described by people with Parkinson's disease: implications for clinical interviewing and the research agenda. Physiother Res Int. 1999;4:190-200.

34. Stack E, Ashburn A, Jupp K. Postural instability during reaching tasks in Parkinson's disease. Physiother Res Int. 2005;10:146-153.

35. Fänge A, Iwarsson S. Changes in accessibility and usability in housing: an exploration of the housing adaptation process. Occup Ther Int. 2005;12:44-59.

36. Leibson C, Maraganore D, Bower J, Ransom J, O’Brien P, Rocca W. Comorbid conditions associated with Parkinson's disease: a populationbased study. Mov Disord. 2006;21:446-455.

37. Lawton MP, Nahemow L. Ecology and the aging process. In: Eisdorfer C, Lawton MP, editors. The Psychology of Adult Development and Aging Washington: American Psychological Association; 1973.
Journal of Parkinsonism \& Restless Legs Syndrome

\section{Publish your work in this journal}

Journal of Parkinsonism and Restless Legs Syndrome is an online, open access, peer-reviewed journal. The journal publishes review articles, historical reviews, original research articles, case reports, letters to the editor, clinical teaching cases, neuroradiology highlights, neuropathology highlights, neuropsychiatry highlights, autobiographies, conference

\section{Dovepress}

proceedings, abstracts and book reviews. The manuscript management system is completely online and includes a very quick and fair peerreview system, which is all easy to use. Visit http://www.dovepress.com/ testimonials.php to read real quotes from published authors. 